\title{
A LITERATURA INFANTIL E O VÍDEO NA ESCO- LA DO HOSPITAL: DIFERENTES LINGUAGENS DE INCLUSÃO SOCIAL
}

\section{CHILDREN'S LITERATURE AND VIDEOS IN SCHOOLS IN HOSPITALS: DIFFERENT LAN- GUAGES FOR SOCIAL INCLUSION}

Ercília Maria Angeli Teixeira de PAULA*

Resumo: Os objetivos deste artigo são descrever e analisar episódios que apontam a importância do vídeo e da literatura infantil para crianças e adolescentes hospitalizados. O artigo é parte dos dados provenientes da pesquisa de campo de uma tese de doutorado. Os fundamentos teórico-metodológicos da tese estiveram pautados na etnografia. A pesquisa de campo foi realizada no período de um ano com filmagens das aulas das professoras da Educação Infantil e do Ensino Fundamental e Médio de uma escola de Hospital Filantrópico na cidade de Salvador-Bahia. O que foi possível verificar é que a literatura infantil e os vídeos produzidos nas salas de aulas do hospital, foram recursos expressivos para as crianças e adolescentes hospitalizados compartilharem dores, alegrias, conhecimentos e repensarem sobre suas condições de vida e de internação. O trabalho com as artes em geral possibilitou compreender o papel dessas diferentes linguagens na escola do hospital como recursos utilizados na inclusão de crianças e adolescentes nas atividades. Também possibilitou entender a forma com a qual as crianças e adolescentes queriam agir, não somente como usuários do serviço de saúde e educação, mas transformadores da realidade e do cotidiano hospitalar.

Palavras-chave: Escola no Hospital. Criança. Adolescente. Inclusão Social.

* Professora do Departamento de Educação e do Programa de Pós Graduação em Educação da Universidade Estadual de Ponta Grossa (DEED/PPGE/UEPG). Mestre em Educação. (USP). Doutora em Educação (UFBA). E.mail: erciliapaula@terra.com.br

Olhar de professor, Ponta Grossa, 10(2): 181-193, 2007. 


\begin{abstract}
This article contains part of the data from the field research of a doctoral thesis whose theoreticalmethodological framework was based on ethnography. Through this article we aim to describe and analyze episodes that point to the importance of videos and children's literature for children and teenagers in hospitals. The field research was carried out during a year and it included the recording of classes from teachers of Childhood, Elementary and Junior High Education in a non-profit school hospital in Salvador - BA. It was possible to verify that children's literature and the videos produced in the classrooms of the hospital were important resources for children and teenagers sharing pain, joy, knowledge and to re-think their life conditions and hospitalization. Working with arts in general allowed us to understand the role these different forms of language have in the schools in hospitals used as resources for the inclusion of children and teenagers in the activities. It also allowed us to understand how children and teenagers wanted to act, not only as users of the health and education services, but also as transformers of reality and of hospital routine.
\end{abstract}

Keywords: School in the Hospital. Child. Teenager. Social Inclusion.

Nas enfermarias dos hospitais infantis públicos no Brasil, até bem pouco tempo atrás, o silêncio, o isolamento e a passividade eram marcas que retratavam o quadro no qual às crianças e adolescentes hospitalizados estavam inseridos.

Nas últimas décadas, com os movimentos de humanização e inclusão social nos hospitais, essas imagens vêem ganhando novos contornos, assumindo diferentes coloridos e significados. Algumas instituições hospitalares já foram planejadas e construídas com arquitetura e mobiliário adaptados para atender às necessidades físicas e também do imaginário das crianças e adolescentes. Nestes espaços, diferentes linguagens se mesclam para compor a harmonia 
do ambiente e a concepção de saúde e tratamento. Estas linguagens estão expressas em diferentes situações: nas pinturas, desenhos com motivos infantis nas paredes das enfermarias, nas obras de arte produzidas pelas crianças e fixadas em murais, nos livros de literatura infanto-juvenil trabalhados. As músicas tocadas nos rádios espalhados pelos corredores, às televisões localizadas nos leitos, os jalecos coloridos enfeitados dos profissionais, os computadores, assim como as atitudes das equipes multidisciplinares demonstram que, a cada dia, os hospitais têm se mobilizado para atender de forma integral a população que atende.

Neste artigo, serão apresentados dados a respeito da pesquisa de campo de uma tese de doutorado desenvolvida em um Hospital Filantrópico na cidade de Salvador na Bahia. Os objetivos da tese estiveram voltados para a compreensão e análise da práxis pedagógica de professoras com crianças e adolescentes que estavam internados neste Hospital.

A etnografia, mais especificamente a etnopesquisa crítica de Macedo (2000) foi o recurso metodológico utilizado que permitiu compreender a relação educação/cultura/diversidade que auxiliaram na construção da história da escola no hospital e produção de seus significados.

A pesquisa de campo ocorreu no período de um ano e foram registradas 55 aulas das professoras em vídeo e diário de campo. As professoras eram da prefeitura municipal de Salvador. Uma professora trabalhava com a Educação Infantil e a outra com Ensino Fundamental e Médio. As análises das aulas e dos diálogos das professoras e alunos permitiram a elaboração de várias categorias da tese. Dentre estas estava a categoria denominada "Etnométodos das práticas pedagógicas das professoras" que descrevia as estratégias utilizadas pelas professoras no cotidiano da realidade escolar hospitalar e as reações apresentadas pelos alunos hospitalizados.

De acordo com Macedo (2000), etnométodos são metodologias constitutivas e relacionadas às culturas dos atores sociais utilizadas por eles para fins práticos com objetivos de compreender e resolver os problemas cotidianos.

Neste artigo, serão apresentados episódios que tratam a respeito do currículo construído pelas professoras na escola do hospital. É preciso destacar que a escola pesquisada funcionava em tempo integral e atendia a crianças e adolescentes com diferentes patologias, 
de cidades e níveis de escolarização diversos.

O projeto pedagógico que se voltava para as crianças e adolescentes no coletivo baseava-se na Pedagogia de Projetos e apresentava temas voltados para a realidade dos alunos. Entretanto, também existiam atividades que as professoras realizavam individualmente com os alunos de acompanhamento da escolarização para que eles não fossem reprovados em suas escolas de origem.

Neste texto, serão apresentadas somente as atividades realizadas pelas professoras que atendiam as crianças em grupo, mais especificamente, uma amostra dos diálogos e ações estabelecidos entre as crianças e as professoras intermediados por histórias da literatura infantil e produção de um vídeo com a professora e alunos.

A escola no hospital apresentava uma variedade de atividades que compunham o currículo. Estas atividades estavam voltadas desde a acolhida das crianças quando elas chegavam ao hospital e eram entrevistadas pelas professoras nos leitos, até as atividades exercidas na sala de aula.

\section{A LITERATURA INFANTIL NO HOSPITAL: A LINGUAGEM DOS CONTOS E DO ACOLHIMENTO}

O trabalho com literatura infantil tem-se mostrado um recurso significativo e muito utilizado no universo hospitalar. Cabe destacar as atividades realizadas por Matos e Muggiati (2001) que desenvolveram Projetos de Literatura Infantil no Hospital Pequeno Príncipe na cidade de Curitiba-PR. Nestes projetos, estudantes de Pedagogia levavam livros infantis até os leitos das crianças e realizavam dramatizações das histórias. Em um outro programa, também desenvolvido por estas professoras, intitulado "Enquanto o Sono não Vem", estudantes de Pedagogia cantavam músicas de ninar e contavam histórias clássicas da literatura infantil para promover o relaxamento das crianças no período noturno no hospital.

Os resultados destes trabalhos evidenciaram que estas atividades tornavam o ambiente hospitalar mais acolhedor e promotor de momentos de imaginação e fantasia, bem como promoviam o sono tranqüilo das crianças auxiliando nos seus processos de cura.

Vale destacar também o Projeto "Biblioteca Viva em Hospitais" descrito por Robles (2005) que é promovido pela Fundação Abrinq pelos Direitos da Criança e Banco Citibank. Este Projeto tem vários 
objetivos: busca promover a reconstituição, preservação da saúde psíquica das crianças hospitalizadas, propicia o alivio das tensões, facilita a integração das crianças e adolescentes no hospital e possibilita que as crianças tenham acesso a livros através da leitura mediada por profissionais e voluntários capacitados em contar histórias para crianças hospitalizadas.

A literatura infantil é considerada um recurso para as crianças terem acesso ao mundo da ficção, da poesia, arte e imaginação e é analisada por estudiosos como Bettelheim (1978), Zilbermann (1987), Coelho (1991) e Corso e Corso (2006). Estes pesquisadores têm contribuído significativamente para o entendimento das ações transformadoras que a literatura promove para os seres humanos.

Bettelheim (1978) considera que o conto de fadas diverte as crianças, esclarece situações para elas mesmas e favorece o desenvolvimento da personalidade e da subjetividade humana. Para ele, os contos estão repletos de significados psicológicos que promovem respostas conscientes e inconscientes na psique das crianças.

Zilbermann (1987) considera que a literatura infantil possui um significado que vai além da estrutura psíquica das pessoas. Para ela, a literatura possibilita ao leitor o reconhecimento da realidade da organização social que o cerca e o acesso ao mundo do imaginário e da fantasia.

Coelho (1991) ao analisar obras clássicas da Literatura Infantil defende a idéia que ela tem como finalidade a instrução e o divertimento.

A literatura infantil no hospital a cada dia vez se expandindo e tem sido utilizada com múltiplos sentidos: terapêutico, educativo, lúdico e de caráter de formação pessoal e intelectual.

A seguir, serão apresentados alguns episódios ocorridos através da literatura infantil na escola no hospital que possibilitaram reflexões para crianças e adolescentes sobre as suas condições de internação e o cotidiano hospitalar.

\section{A LITERATURA INFANTIL NO HOSPITAL PARA ANA: RE- FLEXÕES E DESDOBRAMENTOS}

Este episódio mostra como o título de uma história infantil, associado às experiências de Ana na enfermaria, lhe possibilitou elaborar vários discursos e significados para a história que lhe foi apresentada. 
É preciso destacar que os nomes dos atores sociais que participaram da pesquisa foram alterados para preservar suas identidades.

Ana era uma criança de cinco anos que foi internada no dia 28/07/03 para fazer uma cirurgia de correção da visão. Ela estava freqüentando a sala de aula da Educação Infantil e o hospital pela primeira vez. Suas falas demonstravam que ambiente hospitalar lhe era bem estranho. Embora estivesse participando da aula, respondendo ativamente as perguntas da professora, ela também estava preocupada e tensa em relação ao contexto pré-cirúrgico.

Ana estava em dieta zero para fazer sua cirurgia e ansiosa com aquele momento, com os profissionais e crianças ao seu redor. Todavia, Ana estava atenta e participativa na exposição da professora, mas, de repente, em sua fala, fazia perguntas como se não estivesse participando do movimento da aula.

Bakhtin (1986) denomina esta situação de metanarrativa. O autor analisou o uso das palavras na comunicação discursiva e mostrou que as palavras têm expressividade, são instrumentos da consciência e que a experiência discursiva individual de cada pessoa se desenvolve em uma constante interação com os enunciados alheios. Desta forma, os enunciados são diálogos e as enunciações não existem isoladas, elas estão em uma cadeia. Estes enunciados, portanto, são apenas elos de uma cadeia e só podem ser compreendidos no interior destas cadeias. Sendo assim, é preciso compreender a linguagem a partir do contexto em que se localiza e perceber que a sua significação varia conforme os momentos vividos das pessoas.

Quando a escola desvincula a palavra de seus contextos trata a linguagem como um sistema de normas fechadas como se as palavras fossem neutras.

Bakhtin (1986) defendia a importância da polifonia em oposição ao monologismo uma vez que na polifonia expressa vários sentidos das palavras em oposição a leituras com sentidos únicos. Esta polifonia descrita por Bakhtin foi evidenciada naquela aula da educação infantil, quando a professora disse o nome da história e Ana questionou:

O nome da história é "Fada Cisco Quase Nada". Rapidamente Ana perguntou: Então ela não tem pé? Violeta: Será? Olha ela aqui e mostrou a Fada Cisco. Uma fadinha bem pequena que morava dentro de uma flor e que tinha pés. 
Esta dúvida de Ana talvez tenha surgido porque nesta aula ocorreu um fato que a deve ter impressionado. Neste dia, dentre os alunos da sala, estava uma criança bem pequena com lábio leporino e uma deformidade física bem visível. Entre o lábio e a boca existia uma abertura muito grande, uma espécie de mutilação que esteticamente causava uma sensação estranha para quem observava. Entretanto, aquela criança era tão meiga que todos a admiravam.

Existem muitas crianças nos hospitais, que não correspondem aos padrões estéticos das crianças consideradas "normais" como as crianças que são mutiladas, queimadas, desnutridas, dentre várias outras patologias as quais apresentam deformidades diversas. Esses aspectos podem levar as crianças, consideradas esteticamente "normais", começarem a repensar sobre essas diferenças que muitas vezes aparecem pouco na sociedade e nas próprias escolas.

Naquele dia, a narrativa de Ana sobre a mutilação dos pés da "Fada Cisco" parecia demonstrar que ela estava começando a pensar, a seu modo, sobre as diferenças entre os homens. É possível que ela estivesse pensando sobre o que é ter tudo, um ser completo e não ter nada ou quase nada, um ser incompleto, uma "Fada que é um Cisco", uma "Fada que não é Quase Nada"?

Ana começou a notar a diferença física presente entre os homens e trouxe a discussão para a aula do que é um ser completo, a partir de um simples título de uma história infantil. Para ela, "Fada Cisco Quase Nada" era uma fada incompleta, sem os pés. Esta "não" estética das pessoas, vivenciada na enfermaria, trouxe para aquela criança elementos para refletir sobre o que era um ser que tem tudo e aquele ser que era "quase nada". Para Ana, ser quase nada era aquela pessoa que não tinha a base, um ser mutilado, que não tinha pés. Ela começou a pensar e construir as diferenças a partir do que não era estético, nos levando a pensar, através de sua fala, sobre como é viver com essa pretensa completude humana.

As palavras de Ana demonstravam o quanto uma obra literária infantil, relacionada às vivências na enfermaria trouxeram-lhe a possibilidade de mergulhar na ficção para dialogar com a realidade que estava vivendo. O mundo real se revelava nas dobras daquela obra literária. Utilizando-se de recursos lingüísticos, Ana questionava e subvertia a ordem das regras através do uso de metáforas, demonstrando a polifonia e os vários sentidos das palavras.

A literatura infantil possibilitou a Ana produzia um pensamento 
divergente, elaborando esquemas criativos de perguntas sobre a existência humana. O simples título da história infantil mobilizou Ana para pensar as questões de identidade e diferença de nossa sociedade.

\section{O MEDO PARA CRIANÇAS HOSPITALIZADAS}

Um outro episódio também ilustrativo sobre o papel da literatura infantil para a reflexão das crianças hospitalizadas a respeito da situação que estavam vivenciado ocorreu em uma atividade realizada pela professora do Ensino Fundamental no dia 29/11/2002. Naquele dia, a professora contou para as crianças a história do "Bichinho do Não". Esta história retratava a vida de um menino que se recusava aceitar o que os pais lhe ofereciam pelo fato de ter "engolido" o "Bichinho do não". O personagem também morria de medo de tomar injeção. Os pais o levaram para o médico que "receitou" para a criança obedecer aos pais e assim foi feito.

As crianças re-apresentaram essa história com fantoches, reelaborando-a. Após contarem a história, a professora iniciou uma discussão sobre medo. Nos diálogos, foi possível perceber que a palavra medo aparecia em diferentes vozes, posições distintas que eram atualizadas por todos:

Professora Girassol: Você tem medo Josi? Josi: Eu tenho. Girassol: De que? Lai: Eu tenho medo de arrancá dente. Girassol: Você tem medo de arrancá dente? Marq: Eu não. Eu arranco meu dente sozinho. Girassol: Você tem medo de alguma coisa Marq? Marq: Eu não. Eu tenho medo desses negócio que vai na veia. Eu tenho medo. Pat: Eu tenho medo. De cobra e de cachorro. E Lu tem medo de alguma coisa? Lu: Eu não. Girassol: Não tem medo de nada? Lu: Não. Só de Benzetacil . Girassol: Só de BENZETACIL? Marcos sorriu e disse: Não, eu não tenho medo não. Lia: Eu tenho medo só de tomar injeção. Girassol: E você tem medo Pat? Tem né? E qual foi o maior sentimento do menino da história? Crianças: Medo. Girassol: O medo. E ter medo é normal? Meninos disseram: Não e as meninas contradizendo disseram ao mesmo tempo: Sim. Girassol: E... Ter medo é extremamente normal? Só as crianças sentem medo? Crianças: Não. Girassol: Os adultos também sentem? Pat: Sente. Minha tia mesmo quando vai tomá Benzetacil. Girassol: E ela aí fica como? Pat: Com medo. 
Foi possível perceber nestes episódios que a literatura, através da ficção, reproduzia a realidade vivida pelas crianças no cotidiano hospitalar, possibilitando o diálogo entre eles. Numa articulação entre literatura, livros, fantoches e vivências dos alunos foi possível rever valores, padrões e conceitos.

A literatura infantil, como exercício da poética e beleza, oportunizou as crianças, refletirem sobre o contexto e também rirem e compartilharem com os amigos e as professoras, os sofrimentos e desafios que viviam no hospital, demonstrando múltiplas relações possíveis entre a ficção e o real.

\section{A PRODUÇÃO DO VÍDEO NO HOSPITAL: MOMENTO DE ARTE, MOVIMENTO E INCLUSÃO SOCIAL}

O processo de introdução da câmera no hospital foi bem demorado pelo fato da necessidade do respeito às crianças e adolescentes que não queriam se expor em momentos desagradáveis de suas vidas. Antes de iniciar as filmagens, foram realizadas observações das aulas, sem a câmera, por um período de quatro meses o que permitiu um contato maior com os atores sociais a fim de que adquirissem confiança no trabalho. Neste período, eles eram informados dos objetivos da pesquisa. A população era muito receptiva a pesquisa. Entretanto, antes de utilizar a câmera nas salas de aula, era como se, enquanto pesquisadora fosse imperceptível no cenário. Porém, quando foram iniciadas as primeiras filmagens, este "status" de pesquisadora foi sendo modificado. As pessoas se aproximavam da câmera e realizavam depoimentos constantes. Novas relações sociais e comunicações foram sendo estabelecidas, não somente com a pesquisadora, mas com seu instrumento de trabalho.

É preciso destacar que a pesquisa foi aprovada pelo Comitê de Ética do Hospital analisado e atendia aos critérios exigidos para realização de um trabalho científico na instituição. Dentre estes critérios, existia a necessidade dos atores sociais serem esclarecidos dos objetivos da pesquisa e assinarem o consentimento informado para autorizarem suas imagens. No total de 250 crianças e adolescentes que participaram da pesquisa, somente uma mãe se recusou a autorizar a filmagem de seu filho. Esta atitude foi respeitada e a criança não foi filmada. Portanto, a pesquisa foi sendo construída intermediada por essas negociações burocráticas e por múltiplas interações sociais. 
Após as filmagens das aulas, as cenas gravadas na televisão da sala de aula eram apresentadas aos atores da pesquisa em um processo de restituição diária do trabalho. Este aspecto gerava momentos significativos de partilhas e de felicidade para pessoas que nunca tinham visto suas imagens refletidas na tela da TV.

Em muitos hospitais brasileiros ainda existem crianças, adolescentes e familiares que nunca tiveram a oportunidade de ter uma fotografia e verem seus rostos expressos em retratos. Essas pessoas são, portanto, excluídas da imagem. Nesta pesquisa em muitas situações, as fotografias eram distribuídas às crianças, aos adolescentes e seus familiares e esta era uma forma de incluí-los no universo imagético.

Nessas situações, ocorria um paradoxo na realidade hospitalar. A internação, correspondia a um momento de dor, mas também, para muitas crianças internadas, era um momento de alegria pelo fato de terem a oportunidade de suas vidas registradas no papel fotográfico e nas fitas de vídeo. Naqueles retratos e nas filmagens, as pessoas não estavam levando somente uma imagem do hospital para suas casas, mas também estavam carregando lembranças, sentimentos, histórias e afetos.

Roberto Bogdan e Sari Biklen (1994), ao descreverem sobre a presença da fotografia e da filmagem no trabalho de campo, consideram que em algumas pesquisas, os investigadores buscam explorar o modo como as pessoas reagem as máquinas fotográficas mas em outras situações: “[...] os investigadores poderão utilizar o impacto de uma máquina fotográfica como um abre latas social para desenvolver a relação com os sujeitos (Bogdan e Biklen,1994, p. 141).

O uso da câmera, no início da pesquisa, não possuía essa finalidade intencional de produzir um estreitamento na interação com as pessoas, entretanto, essas aproximações foram ocorrendo quase que naturalmente.

Há muitos anos no Brasil, o pesquisador Sodré (1999), estuda as implicações psicossociais do desenvolvimento das imagens, as formas de relações sociais, os jogos de poder que estão por trás dos fenômenos da indústria cultural e do narcisismo de massa. Ao analisar as relações de poder e dos indivíduos com televisão, ele apresentou uma pesquisa que foi realizada na favela da Rocinha no Rio de Janeiro. Neste trabalho, a pesquisadora, ao entrevistar uma criança, que era engraxate, lhe perguntou: "O que você gostaria de ver na televisão?" $\mathrm{E}$ a criança prontamente lhe respondeu: "Eu". 
Este fato da criança querer se ver na televisão, para Sodré (1999) simbolizava que ela estava querendo se assumir como um indivíduo concreto e não somente como um telespectador infanto - juvenil interessado em uma programação voltada para a infância. Aquela criança expressava o desejo de ver sua imagem refletida no moderno espelho eletrônico, que é a televisão. A criança idealizava ver sua imagem multiplicada, em uma espécie de compensação de uma provável auto-imagem negativa, assim como sonhava que essa imagem pudesse vir a modificar o seu status social de engraxate. Para o autor, a fascinação de ver-se, não é um fenômeno dos tempos modernos, pois a lenda mitológica de Narciso, já expressava a idéia da sedução do belo, do olhar. Narciso, ao debruçar-se sobre a própria imagem, se deixou morrer em um processo onde o olhar passou a assumir um duplo movimento: de possuir e ser possuído.

$\mathrm{Na}$ escola do hospital, o fato de poder aparecer na televisão fascinava as crianças e adolescentes e os mobilizou para uma interação maior com a câmera. A linguagem do vídeo os encantou. Desta maneira, as crianças e adolescentes reivindicaram a sua participação na pesquisa, mas não somente como atores sociais, mas também como diretores das cenas. Elas queriam ser protagonistas juvenis e mostrarem as suas potencialidades. Esta aproximação das crianças e adolescentes hospitalizados com a câmera era uma tentativa de se verem "espelhados" na televisão.

Neste veículo de comunicação, as crianças que aparecem retratadas, normalmente são esteticamente belas e saudáveis, muitas vezes até, com pouco talento. Há pouco tempo no Brasil a televisão vem retratando as crianças afro descendentes, indígenas e as portadores de necessidades especiais, mas ainda pouco espaço é destinado às crianças e adolescentes hospitalizados. Quando são inseridas nas programações, geralmente são retratadas com perspectivas assistencialistas e filantrópicas para se arrecadar fundos e doações. Embora essas ações sejam necessárias, são insuficientes e transmitem, na maior parte das vezes, uma concepção de criança incapaz.

$\mathrm{Na}$ pesquisa desenvolvida na tese de doutorado, o que foi possível comprovar é que as crianças e adolescentes através das imagens, não queriam ser tratadas somente como objeto de piedade e compaixão, mas queriam ser como todas as outras pessoas de suas idades.

Este aspecto foi possível de ser evidenciado no dia 16/06/2003 
com as crianças e os adolescentes que participavam das aulas da professora do Ensino Fundamental e Médio. Eles expressaram o desejo de se apropriar da câmera e explorá-la nas mais diversas circunstâncias. A professora do Ensino Fundamental, por ser aberta a novas propostas e por trabalhar com uma proposta de educação multicultural, inseriu a gravação em vídeo na sua aula. Em conjunto com os alunos, ela elaborou um roteiro de perguntas para entrevistar os familiares das crianças, os quais estavam nas enfermarias.

O objetivo do trabalho era que contassem a respeito das suas experiências com suas escolas na infância. Na produção do roteiro, as crianças, através de suas vozes, apresentaram indagações que possuíam a respeito da organização das escolas no passado e também esboçavam os sonhos que possuíam das escolas que desejam para o futuro. Neste processo de preparação do trabalho, foi realizada uma eleição, democraticamente, foram escolhidos o repórter e o cinegrafista. Com a câmera nas mãos, criativamente as crianças assumiram a direção do trabalho e revolucionaram as enfermarias.

As crianças também fizeram a proposta para que, os amigos que estavam nas enfermarias, que não podiam se locomover até a sala de aula, também fossem entrevistados e incluídos no trabalho. Desta maneira, as crianças foram para os quartos e, nos diálogos realizados com as gerações mais antigas e as mais novas, puderam conhecer diferentes mundos.

Aquela aula demonstrou as possibilidades que a câmera de vídeo, a televisão e as imagens trouxeram para a escola hospital. Em um primeiro momento, o fato das crianças e seus familiares poderem se ver na televisão do hospital, fez com que eles se sentissem incluídos na dinâmica social e televisiva. Mas, se em princípio, havia um contentamento com esta situação, com o tempo, as crianças não queriam somente ver suas imagens refletidas no espelho da TV, este aspecto já não lhes era mais suficiente. Assim como o mito de Narciso, as crianças inicialmente sentiram-se seduzidas por verem suas imagens no "espelho" da televisão, mas elas não queriam ser devoradas por esse espelho e foram inventando outros movimentos. Elas continuavam reivindicando a retratação de suas imagens, mas também solicitaram levar esses espelhos para seus amigos e familiares que estavam nas enfermarias. As crianças também não queriam somente ser observadas e se observarem na televisão, mas queriam realizar a inversão de papéis. Elas passaram de observados para observadores e 
assim, contemplaram também seus amigos nos espelhos da televisão. Esse movimento das imagens possibilitou àquelas crianças sentiremse pessoas capazes, quebrando paradigmas que essas crianças são passivas, que esperam pacientemente a cura.

A produção deste vídeo pelas crianças o trabalho com literatura infantil e com as artes em geral, possibilitou entender a importância da utilização destas diferentes linguagens na escola do hospital e compreender a forma com a qual aquelas crianças queriam agir, não somente sendo usuários do serviço de saúde e educação, mas participando, construindo e transformando a realidade e o cotidiano hospitalar.

\section{REFERÊNCIAS}

BAKHTIN, M. Marxismo e filosofia da linguagem. 3. ed. São Paulo: Hucitec, 1986

BETTELHEIM, B. A psicanálise dos contos de fadas. Rio de Janeiro: Paz e Terra, 1978

BOGDAN, R. C.; BIKLEN, S. K. Investigação qualitativa em educação: uma introdução a teoria e aos métodos. Trad, Maria João Alvarez, Sara B. dos Santos e Telmo M. Baptista. Portugal: Porto Editora, 1994

COELHO, N. N. Literatura infantil. São Paulo: Ática, 1991

CORSO, D.L,; CORSO, M. Fadas no divã: psicanálise nas histórias infantis. Porto Alegre: Artmed, 2006

MACEDO, R. S. A etnopesquisa crítica e multirreferencial nas ciências humanas e na educação. Salvador: EDUFBA, 2000

MATOS, E. L. M.; MUGGiATI, M. M. T. Pedagogia hospitalar. Curitiba: Champagnat, 2001

ROBLES, R. M. Projeto Biblioteca Viva em Hospitais. Disponível em http:// www.unifesp.br/spdm/hsp/humaniza/p33.htm. Acesso em 14/11/2005

SODRÉ, M. A máquina de Narciso: televisão, indivíduo e poder no Brasil. São Paulo: Cortez, 1990.

ZILBERMAN, R. A literatura infantil na escola. São Paulo: Global, 1987.

Encaminhado em: 19/03/07

Aceito em: 24/05/07 